\title{
Suicide - A Preventable Death
}

Suicide is among the ten leading cause of death in most countries and the second most common cause of death in young people ${ }^{1}$.Men commit suicide more than four times as often as women. Women however are four times more likely to attempt suicide than men. Common methods of suicide among men are firearms, hanging, jumping from high places in comparison to women who use drugs, poison etc. However the most common method of suicide is hanging ${ }^{2}$. Presence of mental disorder is one of the strongest risk factor in suicidal attempt and suicidal death ${ }^{3,4}$. Indeed psychological autopsy studies suggest that more than $90 \%$ of people who die by suicide have a diagnosable mental disorder ${ }^{5}$.Though mental disorder is associated with an eleven fold increase in the risk of suicide but the risk is not uniformed overtime ${ }^{3}$. A review of 31 studies from around the world involving 14,629 cases of suicide reported that $98 \%$ of them had International Classification of Diseases (ICD) or Diagnostic \& Statistical Manual of Mental Disorder (DSM) mental disorder at the time of death ${ }^{6}$. The association of mental disorder with suicide is consistent across all settings. Study revealed that approximately $80 \%$ of suicide attempts in United States have a temporally prior mental disorder. Anxiety, mood, impulse control and substance use disorder all significantly predicts subsequent suicide attempt ${ }^{7}$. This issue of journal of Bangladesh College of Physicians and Surgeons published an article " Psychiatric disorders among suicidal behavior patients attending mental health facilities : Adescriptive cross sectional study " revealed the findings that $65 \%$ of the 120 suicidal behavior patients had psychiatric disorder. This article also delineated that $19 \%$ of neurotic disorder, $15 \%$ psychotic disorder, $39 \%$ of personality disorder, $11 \%$ of mood disorder and $04 \%$ of substance use disorder had suicidal behavior which almost commensurate with the result of above mentioned study of United States.

Suicide is a complex and multifaceted behavior. Etiology of suicide needs to be addressed in at least two models. In sociological model of suicide, suicidal behavior is viewed as a relationship between the individual and wider community where individual commits suicide for the sake of wider group (altruistic suicide) or where society impairs individual's freedom (Fatalistic suicide) or where individual no longer feels a sense of community (Egoistic suicide) or where society is inadequate to control social norms (anomic suicide $)^{8,9}$. The most influential clinical model of suicidal behavior is the stress-diathesis or stress vulnerability model where individual carry with them predisposition to suicidal behavior when encounter with a stressor ${ }^{10}$. This concept assumes the existence of an underlying and persistent vulnerability that is made up of biological and psychological trait characteristics. So along with the clinical model social stressor including domestic violence, eve teasing, physical and sexual assault, demands for dowry, failure in examination, breaking relationship or other frustration should be considered in the context of our society.

It is a matter of great concern that when the rate of suicide is in downtrend in the countries of European Union or United States ${ }^{10,11}$, rate of suicide is sharply increasing in Bangladesh from 10,200 in 2014 to 10,500 in 2015 to 11,095 in $2017^{12}$. Data from Police Headquarters, Dhaka, Bangladesh revealed that on an average 30 people kill themselves every day ${ }^{12}$.

Suicidal death is "preventable death". Most of the predictors of suicide are known. The issue of suicide prevention should be addressed efficiently with a multifaceted examination of psychological, cultural, social, economic and religious factors.

A clinician has several practical preventive measures for dealing with a suicidal person, like reducing the psychological pain by modifying patient's stressful environment; enlisting aids for the individual in respect of spouse, employer or friend; building realistic support by recognizing that the patient may have a legitimate complaints and offering alternative to suicide.

The other approach in preventing suicide may be in accordance with National Suicide Prevention Strategy of other standard country like England by

- Reducing risk in key high risk group that includes the person with history of mental disorder and history of self-harm. It has been seen about $40 \%$ of youth who complete suicide $40 \%$ of them had previous attempt.

- Promote mental well-being in the wider population.

- Reduce availability and lethality of suicide methods.

- Improving reporting of suicidal behavior in media.

- Promote research on suicide \& suicide prevention etc $^{13}$. 
Government has the responsibility to develop a policy and concrete actions by making suicide as the important public health issues. Government can implement the existing law the Section 306 and 309 of penal code 1860 strictly to curb down the suicide \& suicidal attempt where it is clearly mentioned that "if any person commits suicide, whoever abets the commission of such suicide, shall be punished with imprisonment of either description for a term which may extend to ten years and shall also be liable to fine (Section 306)". "A person who survives an attempt to suicide will also be liable for his intended action and has to face legal consequences. Attempt to commit suicide is punishable with imprisonment for a term which may extend to one year or with fine or with both (Section 309)"14.

We also should remember that people do not commit suicide to kill themselves; they do it to kill the pain they suffer from within. So it is important to build public awareness involving government and nongovernment agencies, mental health services, primary health care services, voluntary organization together to prevent suicide.

(J Bangladesh Coll Phys Surg 2019; 37: 107-108)

DOI: https://doi.org/10.3329/jbcps.v37i3.41731

\section{Prof. Brig Gen Md. Azizul Islam}

Prof \& Adviser Specialist in Psychiatry Armed Forces Medical College \& CMH, Dhaka

\section{References:}

1. Hawton $\mathrm{K}$ et al. Self-Harm in oxford 2013. Centre for suicide research, University of oxford,oxford.

2. Benjamin JS, Virginia AS. Synopsis of Psychiatry $10^{\text {th }}$ edition, Lippincott Williams and Wilkins, Philadelphia,USA.2007; p.897

3. Harris EC, Barraclough B. Suicide as an outcome for mental Disorder. A meta-analysis Br J Psychiatry. 1997;170:205-228

4. Pokorny AD. Prediction of suicide in Psychiatric patients. Report of a prospective study. Arch Gen Psychiatry.1983;40:249-257

5. Cavanagh JT. Carson AJ. Sharpe M.Lawrie SM. Psychological autopsy studies of suicide: a systematic review. Psychol Med. 2003;33:395-405

6. Bertolote J.M. Fleischmann A (2001). Suicide and a psychiatric diagnosis : a world-wide perspective. World psychiatry. 1:181-5

7. MK Nock. I Hwang, NA Sampson \& RC Kessler. Mental Disorder, Comorbidity \& suicidal behavior: Results from the National comorbidity Survey Replication. Molecular Psychiatry (2010).15,868,876

8. Durkheim E (1951). Suicide. New York : Free press. Original work published 1897

9. Bille-Brahe U (2000). Sociology and suicidal behavior. In K . Hawton \& K van Heeringen, eds. N suicide and attempted suicide, chichester : wiley, pp.193-207

10. Mann J.J (2002) A Current perspective of suicide \& attempted suicide in importance to research. Br J.Psychiatry.178:465-8

11. Chishti P. Stone DH. Corcoran P. et al (2005). Suicide mortality in European Unioin. Eur J Public Health. 13 : 108-14

12. Amanur Rahman Roney. Suicide on the rise in Bangladesh. The Dhaka Tribune March 27, 2018

13. Department of Health (2002). National suicide prevention strategy for England, London: Her Majestys stationary office.

14. The penal code 1860 of Bangladesh. Section $306 \& 309$, chapter XVI of offences affecting human body. 